\title{
Central Pain in Parkinson's Disease: A Case Report
}

\author{
Roger S. Moon*, Yong-Jian Lin, Howard L. Rosner \\ Cedars-Sinai Medical Center, Los Angeles, CA, USA \\ Email: *rmooncs@gmail.com
}

How to cite this paper: Moon, R.S., Lin, Y.-J. and Rosner, H.L. (2018) Central Pain in Parkinson's Disease: A Case Report. Case Reports in Clinical Medicine, 7, 297-305.

https://doi.org/10.4236/crcm.2018.74027

Received: December 18, 2017

Accepted: April 24, 2018

Published: April 27, 2018

Copyright @ 2018 by authors and Scientific Research Publishing Inc. This work is licensed under the Creative Commons Attribution International License (CC BY 4.0).

http://creativecommons.org/licenses/by/4.0/

\section{cc) (i) Open Access}

\begin{abstract}
Pain in Parkinson's disease is common, with an estimated prevalence up to $85 \%$ of those with the disease. Central pain in Parkinson's disease is poorly understood and the role of pharmacological treatment, including the use of dopamine agonists, needs further investigation. Our objective is to discuss a case report of central pain in Parkinson's disease in an outpatient setting. A 67-year-old-male patient with Parkinson's disease presented with right-sided pain, which was refractory to non-steroidal anti-inflammatory drugs, acetaminophen, and opioid agonists. The initiation of dopaminergic therapy resulted in a near complete relief of pain. This case illustrates the need for a multidisciplinary approach to better care for Parkinson's disease patients with central pain, and further study to identify the pathophysiologic mechanism.
\end{abstract}

\section{Keywords}

Central Pain, Parkinson's Disease, Dopamine, Dopaminergic

\section{Introduction}

Parkinson's disease (PD) affects approximately 7 million people in the world [1], estimated to affect $1.6 \%$ of patients aged 65 and above in some countries [2]. The disease costs up to 23 billion annually in the United States [3]. PD is widely recognized by its motor characteristics, however there are well-described non-motor manifestations such as dementia, major depression, sleep disorder, autonomic dysfunction, and pain. The estimated prevalence of pain in PD varies widely and can be up to $85 \%$ of patients [4]. This may largely reflect musculoskeletal [4] [5] [6] [7] and arthralgias secondary to dystonia [8] [9] [10] [11]. However, it is observed that pain persists in regions unaffected by dystonia [6] [12], which may involve a commonly overlooked and poorly understood etiology of central pain. 
Early clinical descriptions of the disease by James Parkinson describe pain and involuntary movement suspected to be beyond that of a peripheral nervous system origin, unrelieved by remedies for inflammatory musculoskeletal disease [13]. Descriptions of pain include lancinating, aching, dull, or burning, and at times, poorly localized. These symptoms are thought to be from direct changes to the central nervous system from the disease itself [14] [15]. The neurophysiological perception of central pain in PD remains poorly understood [9], with an incidence of $1 \%$ [6] to $4.5 \%$ [11] in those with the disease. We present a case in which a PD patient was treated with a dopaminergic agonist, with drastic improvement of pain symptoms.

\section{Case Report}

A 67-year-old male, former transit operator, presented to our clinic with gradual onset of right upper and lower extremity pain and weakness for 6 months. The pain was characterized by "burning and aching", and associated with subjective right upper extremity weakness. His pain was increased with emotional stress and was progressively exacerbated as he developed a tremor, rigidity, and bradykinesia within his right hemi body.

Oral analgesics at presentation included acetaminophen-oxycodone and NSAIDs. His physical examination revealed a resting tremor and hyperreflexia of the right upper and lower extremities. Imaging studies included a brain MRI without contrast which was unremarkable for an infarct, but of limited diagnostic value due to motion artifact. A cervical spine MRI revealed minimal degenerative changes involving C3-4, C5-6, and C6-7, and foraminal stenosis of C5-6 with no cord signal abnormalities. Shortly after his consultation, he underwent an evaluation for Parkinson's disease with a neurologist. An EEG revealed frontotemporal slowing, most notable on the left, without epileptiform activity.

Trials of multiple analgesics, including short acting opioids and acetaminophen were not successful. His pain only mildly responded to NSAID therapy. The patient did not respond well to strong mu-opioid agonistic medications. His consulting neurologist initiated levodopa-carbidopa at 25/100mg every 3 hours for several months. The intensity of the burning pain in his right upper and lower extremity was decreased by the next clinic visit, and he was maintained on the same dosing schedule for one year. He was later trialed on scheduled pregabalin and tramadol with favorable results. He was thus encouraged to continue his medications, and during a subsequent visit, his pain had significantly resolved. Additionally, his rigidity improved, and he no longer had evidence of a tremor during his following clinic visits.

\section{Discussion}

The exact factors which lead to a central pain syndrome in PD are complex and remain poorly understood. The cortical-basal ganglia-thalamic circuit appears to be seen as the integration site for sensory processes including pain, and changes 
in signaling have effects on functional, behavioral, and adaptive strategies important in central pain. It is known that electrophysiological conduction is normal in peripheral and central pain pathways in patients with the disease [16]. This may suggest that processes involved are related to neurochemical alterations including feedback and feed-forward loops that require further study.

Central pain was originally described in 1906 as primarily involving the thalamus, thus developing the name thalamic pain syndrome [17]. Regions of the thalamus typically implicated are the ventral posterolateral and ventral posteromedial regions, however it has been shown that central pain after stroke also known as central post-stroke pain [CPSP] may occur after any lesion throughout a tract [18]. The spinothalamic tract, along with the trigeminothalamic and lemniscal pathways composes the major pathway involved in the central processing of pain [19]. The accepted theory which explains pain after a cerebral lesion was first described in 1911, and was thought to be due to thalamic over activation triggered after an insult to a major sensory pathway involved in pain processing [20].

In $\mathrm{PD}$, the pathophysiology exists in the basal ganglia and its pathways involve adjacent structures including the thalamus and cerebral cortex, along with the complex regulation of dopaminergic activity [21]. This is known as the cortico-basal ganglia-thalamic pathway. The basal ganglia receive information from cortex as well as subcortical structures involved in the processing of pain.

Animal models have shown that dopamine depletion leads to increased responses to nociception and somatosensory input, including MPTP [22] and intrastriatal 6-OHDA models [23] [24]. Electrolytic lesions of the substantia nigra have been observed to reduce analgesic effects of morphine [25]. Previous studies in cats [26] and rodents [27] [28] have shown that the basal ganglia are important in the integration of motor and sensory input, which may play a role in coordination.

Further animal studies suggest dopaminergic activity plays a fundamental role in pain signaling in the cortico-basal ganglia-thalamic pathway. Aversive stimuli in rats were associated with increased dopaminergic activity in the substantia nigra when observed in vivo [29]. Activation of the D1 and D2 receptors in the nigrostriatal pathway and has been correlated with pain suppression in rodents [24] [30] [31]. However D2 antagonism has also been observed to have anti-nociception properties [32] [33], and this has been thought to be via an opioid related mechanism [34]. Burkey et al. [35] described a descending inhibitory mechanism of pain prevalent within a communicating pathway between the insular cortex and the basal ganglia. He later confirmed dose dependent anti-nociceptive activity through electrophysiological recording after introducing a dopamine reuptake inhibitor to the insular cortex [36].

In humans, multiple clinical studies further elucidate the factors contributory to central pain after a lesion in the cortico-basal ganglia-thalamic pathway. Degeneration of the dopaminergic neurons in the nigrostriatal pathway plays a role in somatosensory function, including changes in pain signaling and processing. 
Observations from functional MRI studies suggest there is basal ganglia involvement in the report of acute and chronic pain [37]. Although the exact mechanism poorly understood, damage to the nigrostrial pathway may lead to alterations in pain perception responsive to dopamine therapy [38] [39] [40]. Alterations in dopaminergic autonomic centers, which are important in the inhibition of pain, lead to differences in pain threshold [41] and habituation [16]. This may manifest clinically as allodynia [42] or hyperalgesia [16], which responds favorably to dopaminergic therapy when compared to controls [16] [38] [43] [44]. This has also been clinically observed in other disorders consisting of neuropathic pain such as painful diabetic neuropathy [45] and herpes zoster [46]. However, not all studies involving the administration of dopaminergic activity has been correlated with decreased pain [47].

Dopamine imbalance also has emotional consequences that may have a large impact on the response to certain stimuli. In healthy human volunteers, the variability of emotional [48] and cognitive [49] responses to pain such as negative affect and fear may be related to dopaminergic activity in the mesolimbic system. It was also suggested that dopamine activity within the nigrostriatal pathway was correlated with variations of sensory and affective interpretations of pain [49]. Martikainen [50] demonstrated that D2 and D3 receptors in the striatum modulate pain and not tactile sensation in healthy patients. This finding was supported by observing dopamine receptor activity [51] and cerebral blood flow [38] using positron emission tomography during transmission of pain.

In our patient, there was a clear description of musculoskeletal symptoms including dystonia and tremor, which worsened his pre-existing right hemibody pain and weakness. This was seen as "atypical Parkinsonism" as his motor and sensory complaints appeared to affect only one side of his body. Nonetheless, this suggests a complex, multifactorial origin of his pain and the need for direct treatment of the underlying disease as the first step in management. Steps following the initiation of anti-parkinsonism medications included acute rehabilitation, cognitive behavioral therapy, and the maintenance of neuropathic pain medications such as pregabalin and tramadol. The patient continues to undergo long-term multidisciplinary management.

Diagnosis and treatment of central pain remains challenging due to other overlapping pain etiologies more commonly seen in PD. Several groups [4] [8] [9] [14] [52] [53] [54] have classified pain in PD into different categories or stages for evaluation and treatment purposes. In the majority of cases, the etiology of pain in PD is multifactorial, involving both peripheral and central processes [14] contributed by motor and non-motor symptoms [55]. We present this case report to illustrate a clinical presentation of central pain in PD and to describe other contributors of pain in $\mathrm{PD}$, which warrant equivocal consideration.

Further study is required to understand the dopaminergic pathophysiology in central pain to improve care for patients with PD. Non-motor symptoms including other types of pain may be exacerbated with dopamine therapy [10] 
[53], which suggest opportunities for targeted drug therapy, but studies are limited. Although a pharmacological approach to treatment was discussed above, a multidisciplinary strategy is crucial in managing central pain in PD. Other approaches, including transcutaneous nerve stimulation, acupuncture, massage therapy, and biofeedback have been used for pain related to a wide variety of neurological conditions. As providers, we must also address the rehabilitative, complementary, and psychological requirements, which are significant to the quality of life of all patients with PD [56]-[62]. This serves to minimize treatment delay and to address any unnecessary side effects, leading to optimal care.

\section{References}

[1] De Lau, L.M. and Breteler, M.M. (2006) Epidemiology of Parkinson's Disease. The Lancet Neurology, 5, 525-535. https://doi.org/10.1016/S1474-4422(06)70471-9

[2] De Rijk, Md., Tzourio, C., Breteler, M., Dartigues, J., Amaducci, L., Lopez-Pousa, S., et al. (1997) Prevalence of Parkinsonism and Parkinson's Disease in Europe: The EUROPARKINSON Collaborative Study. European Community Concerted Action on the Epidemiology of Parkinson's Disease. Journal of Neurology, Neurosurgery \& Psychiatry, 62, 10-15. https://doi.org/10.1136/jnnp.62.1.10

[3] Huse, D.M., Schulman, K., Orsini, L., Castelli-Haley, J., Kennedy, S. and Lenhart, G. (2005) Burden of Illness in Parkinson's Disease. Movement Disorders, 20, 1449-1454. https://doi.org/10.1002/mds.20609

[4] Lee, M.A., Walker, R.W., Hildreth, T.J. and Prentice, W.M. (2006) A Survey of Pain in Idiopathic Parkinson's Disease. Journal of Pain and Symptom Management, 32, 462-469. https://doi.org/10.1016/j.jpainsymman.2006.05.020

[5] Hanagasi, H.A., Akat, S., Gurvit, H., Yazici, J. and Emre, M. (2011) Pain Is Common in Parkinson's Disease. Clinical Neurology and Neurosurgery, 113, 11-13. https://doi.org/10.1016/j.clineuro.2010.07.024

[6] Tinazzi, M., Del Vesco, C., Fincati, E., Ottaviani, S., Smania, N., Moretto, G., et al. (2006) Pain and Motor Complications in Parkinson's Disease. Journal of Neurology, Neurosurgery \& Psychiatry, 77, 822-825. https://doi.org/10.1136/jnnp.2005.079053

[7] Kim, Y.E., Lee, W.-W., Yun, J.Y., Yang, H.J., Kim, H.-J. and Jeon, B.S. (2013) Musculoskeletal Problems in Parkinson's Disease: Neglected Issues. Parkinsonism \& Related Disorders, 19, 666-669. https://doi.org/10.1016/j.parkreldis.2013.03.002

[8] Goetz, C.G., Tanner, C.M., Levy, M., Wilson, R.S. and Garron, D.C. (1986) Pain in Parkinson's Disease. Movement Disorders, 1, 45-49. https://doi.org/10.1002/mds.870010106

[9] Ford, B. (1997) Pain in Parkinson's disease. Clinical Neuroscience (New York, NY), 5, 63-72.

[10] Quinn, N., Lang, A., Koller, W. and Marsden, C. (1986) Painful Parkinson's Disease. The Lancet, 327, 1366-1369. https://doi.org/10.1016/S0140-6736(86)91674-0

[11] Defazio, G., Berardelli, A., Fabbrini, G., Martino, D., Fincati, E., Fiaschi, A., et al. (2008) Pain as a Nonmotor Symptom of Parkinson Disease: Evidence from a Case-Control Study. Archives of Neurology, 65, 1191-1194. https://doi.org/10.1001/archneurol.2008.2

[12] Ilson, J., Fahn, S. and Côté, L. (1984) Painful Dystonic Spasms in Parkinson's Disease. Advances in Neurology, 40, 395.

[13] Parkinson, J. (2002) An Essay on the Shaking Palsy. The Journal of Neuropsychiatry 
and Clinical Neurosciences, 14, 223-236. https://doi.org/10.1176/jnp.14.2.223

[14] Snider, S.R., Fahn, S., Isgreen, W.P. and Cote, L.J. (1976) Primary Sensory Symptoms in Parkinsonism. Neurology, 26, 423. https://doi.org/10.1212/WNL.26.5.423

[15] Fil, A., Cano-de-la-Cuerda, R., Muñoz-Hellín, E., Vela, L., Ramiro-González, M. and Fernández-de-las-Peñas, C. (2013) Pain in Parkinson Disease: A Review of the Literature. Parkinsonism \& Related Disorders, 19, 285-294. https://doi.org/10.1016/j.parkreldis.2012.11.009

[16] Schestatsky, P., Kumru, H., Valls-Sole, J., Valldeoriola, F., Marti, M., Tolosa, E., et al. (2007) Neurophysiologic Study of Central Pain in Patients with Parkinson Disease. Neurology, 69, 162-169. https://doi.org/10.1212/01.wnl.0000295669.12443.d3

[17] Dejerine, J. and Roussy, G. (1906) Le Syndrome Thalamique. Revista De Neurologia, 14, 521-532.

[18] Kumar, G. and Soni, C.R. (2009) Central Post-Stroke Pain: Current Evidence. Journal of the Neurological Sciences, 284, 10-17. https://doi.org/10.1016/j.jns.2009.04.030

[19] Willis, W. and Westlund, K. (1997) Neuroanatomy of the Pain System and of the Pathways That Modulate Pain. Journal of Clinical Neurophysiology, 14, 2-31. https://doi.org/10.1097/00004691-199701000-00002

[20] Head, H. and Holmes, G. (1911) Sensory Disturbances from Cerebral Lesions. Brain, 34, 102-254. https://doi.org/10.1093/brain/34.2-3.102

[21] Obeso, J.A., Marin, C., Rodriguez-Oroz, C., Blesa, J., Benitez-Temiño, B., Mena-Segovia, J., et al. (2008) The Basal Ganglia in Parkinson's Disease: Current Concepts and Unexplained Observations. Annals of Neurology, 64, S30-S46. https://doi.org/10.1002/ana.21481

[22] Rosland, J.H., Hunskaar, S., Broch, O.J. and Hole, K. (1992) Acute and Long Term Effects of 1-Methyl-4-phenyl-1, 2, 3, 6-tetrahydropyridine (MPTP) in Tests of Nociception in Mice. Pharmacology \& Toxicology, 70, 31-37. https://doi.org/10.1111/j.1600-0773.1992.tb00421.x

[23] Chudler, E.H. and Lu, Y. (2008) Nociceptive Behavioral Responses to Chemical, Thermal and Mechanical Stimulation after Unilateral, Intrastriatal Administration of 6-hydroxydopamine. Brain Research, 1213, 41-47. https://doi.org/10.1016/j.brainres.2008.03.053

[24] Lin, M., Wu, J., Chandra, A. and Tsay, B. (1981) Activation of Striatal Dopamine Receptors Induces Pain Inhibition in Rats. Journal of Neural Transmission, 51, 213-222. https://doi.org/10.1007/BF01248953

[25] Baumeister, A.A., Nagy, M., Hebert, G., Hawkins, M.F., Vaughn, A. and Chatellier, M.O. (1990) Further Studies of the Effects of Intranigral Morphine on Behavioral Responses to Noxious Stimuli. Brain Research, 525, 115-125. https://doi.org/10.1016/0006-8993(90)91326-C

[26] Nagy, A., Eördegh, G., Paróczy, Z., Márkus, Z. and Benedek, G. (2006) Multisensory Integration in the Basal Ganglia. European Journal of Neuroscience, 24, 917-924. https://doi.org/10.1111/j.1460-9568.2006.04942.x

[27] Chudler, E.H. (1998) Response Properties of Neurons in the Caudate-Putamen and Globus Pallidus to Noxious and Non-Noxious Thermal Stimulation in Anesthetized Rats. Brain Research, 812, 283-288. https://doi.org/10.1016/S0006-8993(98)00971-8

[28] Reig, R. and Silberberg, G. (2014) Multisensory Integration in the Mouse Striatum. Neuron, 83, 1200-1212. https://doi.org/10.1016/j.neuron.2014.07.033

[29] Brown, M.T., Henny, P., Bolam, J.P. and Magill, P.J. (2009) Activity of Neurochem- 
ically Heterogeneous Dopaminergic Neurons in the Substantia nigra during Spontaneous and Driven Changes in Brain State. Journal of Neuroscience, 29, 2915-2925. https://doi.org/10.1523/JNEUROSCI.4423-08.2009

[30] Altier, N. and Stewart, J. (1998) Dopamine Receptor Antagonists in the Nucleus Accumbens Attenuate Analgesia Induced by Ventral Tegmental Area Substance P or Morphine and by Nucleus Accumbens Amphetamine. Journal of Pharmacology and Experimental Therapeutics, 285, 208-215.

[31] Mansikka, H., Erbs, E., Borrelli, E. and Pertovaara, A. (2005) Influence of the Dopamine D2 Receptor Knockout on Pain-Related Behavior in the Mouse. Brain Research, 1052, 82-87. https://doi.org/10.1016/j.brainres.2005.06.021

[32] Schreiber, S., Backer, M.M., Weizman, R. and Pick, C.G. (1997) Augmentation of Opioid Induced Antinociception by the Atypical Antipsychotic Drug Risperidone in Mice. Neuroscience Letters, 228, 25-28. https://doi.org/10.1016/S0304-3940(97)00345-5

[33] Factor, S.A. and Friedman, J.H. (1997) The Emergin Role of Clozapine in the Treatment of Movement Disorders. Movement Disorders, 12, 483-496. https://doi.org/10.1002/mds.870120403

[34] Weizman, T., Pick, C.G., Backer, M.M., Rigai, T., Bloch, M. and Schreiber, S. (2003) The Antinociceptive Effect of Amisulpride in Mice Is Mediated through Opioid Mechanisms. European Journal of Pharmacology, 478, 155-159. https://doi.org/10.1016/j.ejphar.2003.08.049

[35] Burkey, A.R., Carstens, E., Wenniger, J.J., Tang, J. and Jasmin, L. (1996) An Opioidergic Cortical Antinociception Triggering Site in the Agranular Insular Cortex of the Rat That Contributes to Morphine Antinociception. Journal of Neuroscience, 16, 6612-6623. https://doi.org/10.1523/JNEUROSCI.16-20-06612.1996

[36] Burkey, A.R., Carstens, E. and Jasmin, L. (1999) Dopamine Reuptake Inhibition in the Rostral Agranular Insular Cortex Produces Antinociception. Journal of Neuros cience, 19, 4169-4179. https://doi.org/10.1523/JNEUROSCI.19-10-04169.1999

[37] Borsook, D., Upadhyay, J., Chudler, E.H. and Becerra, L. (2010) A Key Role of the Basal Ganglia in Pain and Analgesia-Insights Gained through Human Functional Imaging. Molecular Pain, 6, 27. https://doi.org/10.1186/1744-8069-6-27

[38] Brefel-Courbon, C., Payoux, P., Thalamas, C., Ory, F., Quelven, I., Chollet, F., et al. (2005) Effect of Levodopa on Pain Threshold in Parkinson's Disease: A Clinical and Positron Emission Tomography Study. Movement Disorders, 20, 1557-1563. https://doi.org/10.1002/mds.20629

[39] Gerdelat-Mas, A., Simonetta-Moreau, M., Thalamas, C., Ory-Magne, F., Slaoui, T., Rascol, O., et al. (2007) Levodopa Raises Objective Pain Threshold in Parkinson's Disease: A RIII Reflex Study. Journal of Neurology, Neurosurgery \& Psychiatry, 78, 1140-1142. https://doi.org/10.1136/jnnp.2007.120212

[40] Battista, A.F. and Wolff, B.B. (1973) Levodopa and Induced-Pain Response: A Study of Patients with Parkinsonian and Pain Syndromes. Archives of Internal Medicine, 132, 70-74. https://doi.org/10.1001/archinte.1973.03650070062009

[41] Djaldetti, R., Shifrin, A., Rogowski, Z., Sprecher, E., Melamed, E. and Yarnitsky, D. (2004) Quantitative Measurement of Pain Sensation in Patients with Parkinson Disease. Neurology, 62, 2171-2175. https://doi.org/10.1212/01.WNL.0000130455.38550.9D

[42] Peyron, R., Schneider, F., Faillenot, I., Convers, P., Barral, F.-G., Garcia-Larrea, L., et al. (2004) An fMRI Study of Cortical Representation of Mechanical Allodynia in 
Patients with Neuropathic Pain. Neurology, 63, 1838-1846. https://doi.org/10.1212/01.WNL.0000144177.61125.85

[43] Lim, S.Y., Farrell, M.J., Gibson, S.J., Helme, R.D., Lang, A.E. and Evans, A.H. (2008) Do Dyskinesia and Pain Share Common Pathophysiological Mechanisms in Parkinson's Disease? Movement Disorders, 23, 1689-1695. https://doi.org/10.1002/mds.22111

[44] Thompson, T., Correll, C.U., Gallop, K., Vancampfort, D. and Stubbs, B. (2016) Is Pain Perception Altered in People with Depression? A Systematic Review and Meta-Analysis of Experimental Pain Research. The Journal of Pain, 17, 1257-1272. https://doi.org/10.1016/j.jpain.2016.08.007

[45] Ertas, M., Sagduyu, A., Arac, N., Uludag, B. and Ertekin, C. (1998) Use of Levodopa to Relieve Pain from Painful Symmetrical Diabetic Polyneuropathy. Pain, 75, 257-259. https://doi.org/10.1016/S0304-3959(98)00003-7

[46] Kernbaum, S. and Hauchecorne, J. (1981) Administration of Levodopa for Relief of Herpes Zoster Pain. JAMA, 246, 132-134. https://doi.org/10.1001/jama.1981.03320020024017

[47] Gierthmühlen, J., Arning, P., Binder, A., Herzog, J., Deuschl, G., Wasner, G., et al. (2010) Influence of Deep Brain Stimulation and Levodopa on Sensory Signs in Parkinson's Disease. Movement Disorders, 25, 1195-1202. https://doi.org/10.1002/mds.23128

[48] Scott, D.J., Heitzeg, M.M., Koeppe, R.A., Stohler, C.S. and Zubieta, J.-K. (2006) Variations in the Human Pain Stress Experience Mediated by Ventral and Dorsal Basal Ganglia Dopamine Activity. Journal of Neuroscience, 26, 10789-10795. https://doi.org/10.1523/JNEUROSCI.2577-06.2006

[49] Chudler, E.H. and Dong, W.K. (1995) The Role of the Basal Ganglia in Nociception and Pain. Pain, 60, 3-38. https://doi.org/10.1016/0304-3959(94)00172-B

[50] Martikainen, I.K., Hagelberg, N., Mansikka, H., Hietala, J., Någren, K., Scheinin, H., et al. (2005) Association of Striatal Dopamine D2/D3 Receptor Binding Potential with Pain But Not Tactile Sensitivity or Placebo Analgesia. Neuroscience Letters, 376, 149-153. https://doi.org/10.1016/j.neulet.2004.11.045

[51] Pertovaara, A., Martikainen, I.K., Hagelberg, N., Mansikka, H., Någren, K., Hietala, J., et al. (2004) Striatal Dopamine D2/D3 Receptor Availability Correlates with Individual Response Characteristics to Pain. European Journal of Neuroscience, 20, 1587-1592. https://doi.org/10.1111/j.1460-9568.2004.03622.x

[52] Chaudhuri, K., Rizos, A., Trenkwalder, C., Rascol, O., Pal, S., Martino, D., et al. (2015) King 's Parkinson's Disease Pain Scale, the First Scale for Pain in PD: An International Validation. Movement Disorders, 30, 1623-1631.

https://doi.org/10.1002/mds.26270

[53] Chaudhuri, K.R., Healy, D.G. and Schapira, A.H. (2006) Non-Motor Symptoms of Parkinson's Disease: Diagnosis and Management. The Lancet Neurology, 5, 235-245. https://doi.org/10.1016/S1474-4422(06)70373-8

[54] Braak, H., Del Tredici, K., Rüb, U., de Vos, R.A., Steur, E.N.J. and Braak, E. (2003) Staging of Brain Pathology Related to Sporadic Parkinson's Disease. Neurobiology of Aging, 24, 197-211. https://doi.org/10.1016/S0197-4580(02)00065-9

[55] Storch, A., Schneider, C.B., Wolz, M., Stürwald, Y., Nebe, A., Odin, P., et al. (2013) Nonmotor Fluctuations in Parkinson Disease Severity and Correlation with Motor Complications. Neurology, 80, 800-809.

https://doi.org/10.1212/WNL.0b013e318285c0ed 
[56] Colosimo, C., Morgante, L., Antonini, A., Barone, P., Avarello, T.P., Bottacchi, E., et al. (2010) Non-Motor Symptoms in Atypical and Secondary Parkinsonism: The PRIAMO Study. Journal of Neurology, 257, 5-14. https://doi.org/10.1007/s00415-009-5255-7

[57] Starkstein, S.E., Preziosi, T.J. and Robinson, R.G. (1991) Sleep Disorders, Pain, and Depression in Parkinson's Disease. European Neurology, 31, 352-355. https://doi.org/10.1159/000116692

[58] Goetz, C.G., Wilson, R.S., Tanner, C.M. and Garron, D.C. (1987) Relationships among Pain, Depression, and Sleep Alterations in Parkinson's Disease. Advances in Neurology, 45, 345-347.

[59] Schrag, A. (2006) Quality of Life and Depression in Parkinson's Disease. Journal of the Neurological Sciences, 248, 151-157. https://doi.org/10.1016/j.jns.2006.05.030

[60] Valkovic, P., Minar, M., Singliarova, H., Harsany, J., Hanakova, M., Martinkova, J., et al. (2015) Pain in Parkinson's Disease: A Cross-Sectional Study of Its Prevalence, Types, and Relationship to Depression and Quality of Life. PLOS ONE, 10, e0136541. https://doi.org/10.1371/journal.pone.0136541

[61] Quittenbaum, B.H. and Grahn, B. (2004) Quality of Life and Pain in Parkinson's Disease: A Controlled Cross-Sectional Study. Parkinsonism \& Related Disorders, 10, 129-136. https://doi.org/10.1016/j.parkreldis.2003.12.001

[62] Price, D.D. (2000) Psychological and Neural Mechanisms of the Affective Dimension of Pain. Science, 288, 1769-1772. https://doi.org/10.1126/science.288.5472.1769 